\title{
Efeitos de fontes e formas de processamento do amido na utilização de nutrientes e parâmetros ruminais de vacas em lactação
}

\author{
[Effects of starch sources and processing on nutrient digestibility and ruminal \\ parameters of lactating cows] \\ J.M.C. Simas ${ }^{1}$, A.V. Pires ${ }^{1 *}$, I. Susin ${ }^{1}$, F.A.P. Santos ${ }^{1}$, C.Q. Mendes ${ }^{1}$, \\ R.C. Oliveira Jr. ${ }^{1}$, J.J.R. Fernandes ${ }^{2}$ \\ ${ }^{1}$ Departamento de Zootecnia - ESALQ-USP \\ Caixa Postal 9 \\ 13418900 - Piracicaba, SP \\ ${ }^{2}$ Departamento de Produção Animal - UFG - Goiânia, GO
}

\begin{abstract}
RESUMO
Cinco vacas holandesas pluríparas, com cânulas no rúmen e no duodeno, foram distribuídas em delineamento de quadrado latino $5 \times 5$. As vacas foram submetidas a cinco rações experimentais contendo $40 \%$ de cana-de-açúcar, $60 \%$ de concentrado e cerca de $30 \%$ de amido. As rações diferiram quanto ao processamento ou à fonte principal do amido utilizado: milho grosseiramente moído, milho finamente moído, milho floculado a $310 \mathrm{~g} / \mathrm{l}$, milho floculado a $360 \mathrm{~g} / \mathrm{l}$ ou raspa de mandioca. Não houve diferença $(\mathrm{P}>0,05)$ no consumo de matéria seca entre os tratamentos. A digestibilidade ruminal do amido foi maior na ração que continha raspa de mandioca. As digestibilidades ruminal da fibra em detergente neutro e da fibra em detergente ácido não diferiram entre os tratamentos. Os dados médios de $\mathrm{pH}$ ruminal se mantiveram acima de 6,0 , exceto às 2 e às 4 h após a alimentação com a dieta que continha raspa de mandioca. Não houve efeito significativo dos tratamentos sobre a concentração de ácidos graxos voláteis totais. O processo de floculação promoveu aumento da digestibilidade do amido do milho, em relação à moagem de forma grosseira. A digestibilidade ruminal do amido presente na raspa de mandioca foi maior do que a do milho, independentemente da forma de processamento utilizada.
\end{abstract}

Palavras-chave: vaca, ácido graxo volátil, degradabilidade in situ, raspa de mandioca, milho floculado, processamento de grãos

\begin{abstract}
Five multiparous lactating Holsteins cows, cannulated in the rumen and proximal duodenum, were used in a $5 \times 5$ latin square. Cows were fed a 40:60 forage: concentrate diet (40\% fresh sugar cane and $60 \%$ concentrate). Diets were formulated to have $30 \%$ of starch and treatments were starch sources and ration processing forms: cracked corn, finely ground corn, flaked corn at $310 \mathrm{~g} / \mathrm{l}$, flaked corn at $360 \mathrm{~g} / \mathrm{l}$, or cassava scrapings. No difference $(P>0.05)$ was observed among treatments for dry matter intake. Starch ruminal digestibility was higher for cassava scrapings treatment. NDF and ADF digestibility were similar among treatments. Average values of ruminal $\mathrm{pH}$ were above 6 , except at 2 and $4 \mathrm{~h}$ after feeding the cassava diet. There was no effect of treatment on concentrations of total volatile fatty acids. The flocculation process increased corn starch digestibility. Ruminal degradability of the cassava scrapings starch was higher than corn, without effect of processing form.
\end{abstract}

Keywords: cow, volatile fatty acid, in situ degradability, flaked corn, grain processing, cassava scrapings

Recebido em 18 de outubro de 2006

Aceito em 2 de agosto de 2008

*Autor para correspondência (corresponding author)

E-mail: alvpires@esalq.usp.br 


\section{INTRODUÇÃO}

Tratamentos térmicos de grãos de cereais, como a floculação do milho e do sorgo, melhoram a utilização desses grãos pelos animais em razão do aumento da digestibilidade do amido no rúmen $\mathrm{e}$, conseqüentemente, no trato digestivo total. $\mathrm{O}$ aumento da degradabilidade ruminal do amido tem-se mostrado útil, não só para maximizar a capacidade fermentativa do rúmen, o que aumenta a síntese de proteína microbiana e a produção de ácidos graxos voláteis, como também permite economia no metabolismo energético do animal hospedeiro. O carboidrato estrutural presente no grão e a matriz protéica dos grânulos de amido são os principais fatores responsáveis pelas diferenças de digestibilidade existentes entre as fontes de amido (McAllister et al., 1993).

A mandioca caracteriza-se por ser rica em carboidratos não estruturais, principalmente em amido. De acordo com Zeoula e Caldas Neto (2001), fontes de amido podem gerar efeitos benéficos nas características de fermentação ruminal, melhorando a utilização dos carboidratos estruturais. O estudo das variáveis de fermentação ruminal do amido da raíz de mandioca é importante para auxiliar a determinação das limitações e dos benefícios da utilização desse ingrediente na alimentação animal.

Diversos trabalhos que compararam fontes de amido utilizaram, com sucesso, a silagem de milho como volumoso. Entretanto, a literatura é deficiente em informações sobre a utilização de fontes de amido em rações que tenham a canade-açúcar como volumoso.

O objetivo deste trabalho foi avaliar a influência do fornecimento de diferentes fontes e formas de processamento do amido na alimentação de vacas em lactação, tendo a cana-de-açúcar como fonte de volumoso, sobre a digestibilidade dos nutrientes no rúmen, no intestino e no trato digestivo total; a degradabilidade in situ do amido e os parâmetros ruminais.

\section{MATERIAL E MÉTODOS}

Cinco vacas holandesas, com cânulas no rúmen e no duodeno proximal, foram utilizadas em delineamento experimental de quadrado latino 5 x 5 durante períodos de 14 dias (10 dias de adaptação e 4 dias de colheita). Os animais foram alojados em instalações do tipo tie-stall, com acesso a comedouro e a bebedouro individuais.

As dietas experimentais (Tab. 1) continham $40 \%$ de cana-de-açúcar, $60 \%$ de concentrado e cerca de $30 \%$ de amido; diferindo quanto ao processamento ou à fonte principal de amido utilizado: milho grosseiramente moído (MGM), milho finamente moído (MFM), milho floculado a 310g/l (MF310), milho floculado a 360g/l (MF360) ou raspa de mandioca (RM). As fontes de amido e formas de seu processamento constituíram os tratamentos experimentais.

Para obtenção da moagem grossa, o milho foi moído em moinho de martelos, com a retirada de duas facas e de todos os seis conjuntos de martelo. Para moagem fina $o$ milho foi processado para a obtenção de fubá. O processo de floculação envolveu a passagem do milho por um conjunto de rolos laminadores, após a exposição ao vapor por 40 a $50 \mathrm{~min}$, e as duas densidades $(310$ e $360 \mathrm{~g} / \mathrm{l})$ foram obtidas mediante regulagem da distância entre os rolos. A densidade do milho floculado foi medida após o processamento com base no peso por unidade de volume contida numa proveta.

O alimento concentrado, preparado previamente, foi misturado ao volumoso no cocho, de forma a se obter mistura homogênea. As rações foram fornecidas ad libitum, duas vezes ao dia, permitindo-se sobras de $5 \%$ a $10 \%$ da quantidade oferecida. Para determinação da média do tamanho de partículas das formas físicas do milho grosseiramente moído, do milho finamente moído e do milho floculado, utilizou-se a técnica de peneiras descrita por $\mathrm{Yu}$ et al. (1998), conforme apresentado na Tab. 2.

As amostras do alimento oferecido e da fração recusada foram colhidas diariamente $\mathrm{e}$ compostas por período e por vaca para posterior análise laboratorial. Amostras do fluído ruminal $(25 \mathrm{ml})$ foram colhidas de cada vaca em intervalos de $2 \mathrm{~h}$ durante o último dia de colheita de cada período e o $\mathrm{pH}$ foi determinado imediatamente após a colheita. As amostras foram congeladas para posterior análise de ácidos graxos voláteis (AGVs) por cromatografia gasosa. 
Tabela 1. Proporção dos ingredientes na ração e composição química das dietas experimentais (\% da MS)

\begin{tabular}{|c|c|c|c|c|c|}
\hline \multirow{2}{*}{ Ingredientes $^{2}$} & \multicolumn{5}{|c|}{ Tratamentos } \\
\hline & MGM & MFM & MF310 & MF360 & RM \\
\hline Cana-de-açúcar & 40,0 & 40,0 & 40,0 & 40,0 & 40,0 \\
\hline Fonte de amido & 35,6 & 35,6 & 35,6 & 35,6 & 28,4 \\
\hline Farelo de soja & 15,3 & 15,3 & 15,3 & 15,3 & 22,6 \\
\hline Caroço de algodão & 5,0 & 5,0 & 5,0 & 5,0 & 5,0 \\
\hline Minerais & 2,46 & 2,43 & 2,43 & 2,43 & 2,43 \\
\hline Uréia & 0,94 & 0,94 & 0,94 & 0,94 & 0,84 \\
\hline Bicarbonato de sódio & 0,7 & 0,7 & 0,7 & 0,7 & 0,7 \\
\hline \multicolumn{6}{|l|}{ Composição química } \\
\hline $\mathrm{PB}, \%$ & 16,96 & 17,27 & 15,15 & 15,88 & 16,97 \\
\hline $\mathrm{EB}, \mathrm{kcal} / \mathrm{kg}$ & 4325 & 4330 & 4291 & 4314 & 4271 \\
\hline ELL, Mcal/kg & 1,58 & 1,6 & 1,56 & 1,56 & 1,57 \\
\hline Amido, $\%$ & 29,27 & 28,06 & 31,92 & 32,54 & 30,91 \\
\hline FDN, \% & 32,24 & 33,49 & 33,69 & 33,25 & 32,11 \\
\hline FDA, \% & 18,40 & 18,32 & 17,49 & 17,54 & 18,99 \\
\hline EE, \% & 2,27 & 3,02 & 2,48 & 1,97 & 1,95 \\
\hline
\end{tabular}

MGM: milho grosseiramente moído; MFM: milho finamente moído; MF310: milho floculado a 310g/l; MF360: milho floculado a 360g/l; RM: raspa de mandioca; PB: proteína bruta; EB: energia bruta; ELL: energia líquida de lactação (Nutrient..., 2001); FDN: fibra insolúvel em detergente neutro; FDA: fibra insolúvel em detergente ácido; EE: extrato etéreo.

Tabela 2. Médias do tamanho de partículas do milho (\% retida na peneira)

\begin{tabular}{lcccccccccc}
\hline \multirow{2}{*}{ Processamento } & $\begin{array}{c}4,00 \\
\mathrm{~mm}\end{array}$ & $\begin{array}{c}2,00 \\
\mathrm{~mm}\end{array}$ & $\begin{array}{c}1,00 \\
\mathrm{~mm}\end{array}$ & $\begin{array}{c}0,85 \\
\mathrm{~mm}\end{array}$ & $\begin{array}{c}0,60 \\
\mathrm{~mm}\end{array}$ & $\begin{array}{c}0,43 \\
\mathrm{~mm}\end{array}$ & $\begin{array}{c}0,25 \\
\mathrm{~mm}\end{array}$ & P.R.P & M.T.P \\
\hline MFM & 1,2 & 9,1 & 33,2 & 11,0 & 10,6 & 9,2 & 8,6 & 5,0 & 12,1 \\
MGM & 21,8 & 53,8 & 14,4 & 2,2 & 2,7 & 1,2 & 1,7 & 2,2 & 4,27 \\
MF & 72,3 & 24,6 & 1,9 & 0,2 & 0,3 & 0,1 & 0,1 & 0,5 & 5,09 \\
\hline
\end{tabular}

MFM: milho finamente moído; MGM: milho grosseiramente moído; MF: milho floculado (360 e 310g/l); P.R.P: $\%$ de partículas retidas no fundo do prato; M.T.P: média do tamanho de partículas que foi calculada pressupondose que o milho retido na peneira de $4 \mathrm{~mm}$ tem média de tamanho de partículas de $6 \mathrm{~mm}$, a qual foi multiplicada pela percentagem retida na peneira de $4 \mathrm{~mm}$. Este valor foi somado ao resultado das médias entre as peneiras maiores e as peneiras menores e multiplicado pelo percentual retido na peneira menor (ex.: MMG $4 \mathrm{~mm}+2 \mathrm{~mm} / 2=3$, que multiplicado por $0,538=1,59 \mathrm{e}$, assim sucessivamente). Admitiu-se que as partículas que passaram pela peneira com crivo de $0,25 \mathrm{~mm}$ tinham $0,12 \mathrm{~mm}$.

O conteúdo duodenal foi amostrado a cada $4 \mathrm{~h}$ durante os quatro dias de colheita de cada período, sendo atrasada em $1 \mathrm{~h} / \mathrm{d}$ para que a amostragem estivesse representada a cada hora de um período de 24h. As amostras foram compostas por vaca e por período e foram congeladas para análise subseqüente.

Amostras de fezes foram colhidas duas vezes ao dia, nos últimos quatro dias de colheita, e o horário de colheita foi adiantado em $4 \mathrm{~h} / \mathrm{d}$ para maior representatividade da amostragem. As amostras foram compostas por vaca e por período, e congeladas $\mathrm{a}-18^{\circ} \mathrm{C}$.

A lignina foi utilizada como marcador interno, para cálculo de fluxos de matéria seca do conteúdo duodenal. A digestibilidade dos nutrientes no rúmen (aparente e verdadeira) e no trato total foi calculada com base nas relações entre os nutrientes e a lignina na dieta, no conteúdo duodenal e nas fezes.

Amostras das dietas, do alimento recusado, do conteúdo duodenal e das fezes foram secadas em estufa de ventilação forçada $\left(55\right.$ a $\left.60^{\circ} \mathrm{C}\right)$ por $72 \mathrm{~h}$ e moídas em moínho do tipo Wiley com peneira com crivos de $1 \mathrm{~mm}$. As dietas experimentais foram analisadas para determinação da matéria seca (MS), da matéria mineral e da proteína bruta de acordo com o A.O.A.C. (Official..., 1990); da fibra em detergente neutro (FDN) e da fibra detergente ácido (FDA), de acordo com os métodos de Van Soest et al. (1991); da lignina de 
acordo com Goering e Van Soest (1970) e da energia bruta em bomba calorimétrica adiabática. A concentração de amido foi determinada de acordo com Poore et al. (1991).

No último dia de cada período de colheita, amostras das respectivas dietas foram incubadas no rúmen para determinação da degradabilidade in situ da matéria seca e do amido das dietas. As amostras (cerca de 5,5g) foram moídas em peneiras com crivos de $2 \mathrm{~mm}$, pesadas e colocadas em sacos de poliéster de $10 \times 15 \mathrm{~cm}$ com média de porosidade de $45 \mu \mathrm{m}$. Os sacos, em duplicata, foram introduzidos no rúmen seqüencialmente, para permanência de 48,36 , $24,12,8,4$ e $2 \mathrm{~h}$.

O milho grosseiramente moído e o milho finamente moído foram considerados como único tratamento, já que as amostras foram moídas a $2 \mathrm{~mm}$ para incubação in situ, o que eliminou o diferencial do tratamento in vivo. Os sacos de poliéster incubados foram removidos simultaneamente, e imediatamente enxaguados com água gelada. Posteriormente, foram determinadas as quantidades residuais de MS e de amido.

Os dados das amostras incubadas foram processados pelo software Fit Curve, desenvolvido pelo Rowett Research Institute, de Aberdeen, na Escócia. Esse software usa o modelo de degradabilidade ruminal de Orskov e McDonald (1979). A degradabilidade potencial in situ foi calculada de acordo com a fórmula:

$$
\mathrm{DG}=\mathrm{a}+\mathrm{b}\left(1-\mathrm{e}^{-\mathrm{ct}}\right) \text { em que: }
$$

DG = degradabilidade estimada; $\mathrm{a}=$ fração rapidamente solúvel em água; $\mathrm{b}=$ fração insolúvel em água, mas potencialmente degradável; $\mathrm{c}=$ taxa de degradação da fração b; e $=$ logaritmo natural; $\mathrm{a}+\mathrm{b}=$ potencial $\mathrm{de}$ degradabilidade e $\mathrm{t}=$ tempo.

A degradabilidade efetiva foi calculada pela fórmula:

$$
\begin{aligned}
& \mathrm{p}=\mathrm{a}+\mathrm{bc} / \mathrm{c}+\mathrm{k} \text { em que: } \\
& \mathrm{k}=\text { taxa de passagem }
\end{aligned}
$$

Os dados foram analisados por meio do PROC GLM (User's..., 1997). As variáveis pH e AGVs foram analisadas como split plot, para detecção de interações entre tratamentos e tempo. Diferenças significativas foram consideradas a $5 \%$ de significância.

\section{RESULTADOS E DISCUSSÃO}

Não houve diferença $(\mathrm{P}>0,05)$ entre tratamentos para o consumo de matéria seca (Tab. 3). No tratamento em que a fonte de amido foi a raspa de mandioca, a digestibilidade ruminal da matéria seca e a digestibilidade ruminal da matéria orgânica foram maiores do que aquelas das demais fontes, em razão da maior digestibilidade da fração amido.

A digestibilidade aparente da $\mathrm{MO}$ no trato digestivo total foi maior para os tratamentos milho floculado a $310 \mathrm{~g} / \mathrm{l}$, milho floculado a $360 \mathrm{~g} / \mathrm{l}$ e raspa de mandioca (Tab. 3). Vários autores também relataram maior digestibilidade da MS e da MO associada à maior digestibilidade ruminal de fontes de amido floculadas ou de alta umidade, comparada à dos grãos laminados ou moídos (Santos, 1996; Santos et al., 1999; Simas et al., 1997; Lykos et al., 1997; Wilkerson et al., 1997).

A raspa de mandioca foi a fonte de amido que apresentou a maior digestibilidade ruminal e a maior fração digerida no rúmen em relação ao total de amido digerido no trato digestivo total. O amido da raspa de mandioca contém cerca de $17 \%$ de amilose, ao passo que os cereais apresentam valores de $25 \%$ a $30 \%$. O baixo teor de amilose confere à mandioca maior susceptibilidade ao ataque enzimático. Outra característica do amido da mandioca, que justifica o aumento de sua digestibilidade, é a ausência de interações com matrizes e corpos protéicos que diminuem a digestibilidade do amido, como no milho (Nocek e Tamminga, 1991).

$\mathrm{O}$ amido do milho grosseiramente moído apresentou a menor digestibilidade, tanto no rúmen como no trato digestivo total, comparada à do milho finamente moído e às do milho floculado. A moagem fina resultou em valores de digestibilidade ruminal e total do amido semelhante aos da floculação (310 ou $360 \mathrm{~g} / \mathrm{l})$ e maiores do que o da moagem grossa. A maior digestibilidade do milho finamente moído comparada à do milho moído de forma grosseira se deveu à maior superfície de contato das partículas de milho que permite maior ataque microbiano ao amido. Já o efeito da floculação, além da maior área superficial, também ocorre em razão das alterações físico-químicas (gelatinização), as quais aumentam a digestibilidade do amido. 
Tabela 3. Efeito das fontes e das formas de processamento do amido na digestibilidade dos nutrientes (\%)

\begin{tabular}{|c|c|c|c|c|c|c|}
\hline \multirow{2}{*}{ Variáveis } & \multicolumn{5}{|c|}{ Tratamentos } & \multirow{2}{*}{ EPM } \\
\hline & MGM & MFM & MF310 & MF360 & $\mathrm{RM}$ & \\
\hline & \multicolumn{6}{|c|}{ Matéria seca } \\
\hline Consumo, $\mathrm{kg} / \mathrm{d}$ & 19,29 & 17,27 & 17,11 & 16,37 & 14,93 & 1,15 \\
\hline Digest ruminal & $33,77 \mathrm{c}$ & $33,19 \mathrm{cb}$ & $46,53 \mathrm{abc}$ & $41,48 b c$ & $51,71 \mathrm{a}$ & 4,39 \\
\hline \multirow[t]{2}{*}{ Digest total } & $66,26 b$ & $65,20 b$ & $70,24 \mathrm{ab}$ & $70,80 \mathrm{a}$ & $74,85 \mathrm{a}$ & 1,56 \\
\hline & \multicolumn{6}{|c|}{ Matéria orgânica } \\
\hline Digest ruminal aparente & $35,53 b$ & $37,19 b$ & $51,15 \mathrm{a}$ & $45,32 \mathrm{ab}$ & $57,06 \mathrm{a}$ & 3,94 \\
\hline Digest ruminal verdadeira & $46,14 b$ & $53,00 \mathrm{~b}$ & $63,10 \mathrm{ab}$ & $60,04 \mathrm{ab}$ & $77,68 \mathrm{a}$ & 4,70 \\
\hline Digest total & $66,88 \mathrm{~b}$ & & $\begin{array}{l}\text { 71,74a } \\
\text { Amido }\end{array}$ & $72,23 a$ & $75,85 \mathrm{a}$ & 1,47 \\
\hline Digest ruminal & $43,44 c$ & $72,46 b$ & $76,97 \mathrm{~b}$ & $65,96 b$ & $91,12 \mathrm{a}$ & 3,99 \\
\hline Digest total & $76,51 \mathrm{a}$ & $92,04 \mathrm{~b}$ & $97,38 b$ & $97,64 b$ & $96,43 b$ & 2,30 \\
\hline \multirow[t]{2}{*}{ Digest ruminal/digest total } & $63,09 \mathrm{c}$ & $74,12 \mathrm{bc}$ & $78,00 \mathrm{~b}$ & $68,02 \mathrm{c}$ & $91,22 \mathrm{a}$ & 4,24 \\
\hline & \multicolumn{6}{|c|}{ Fibra em detergente neutro } \\
\hline Digest ruminal & $50,53 a$ & $40,33 b$ & $44,32 \mathrm{ab}$ & $43,6 a b$ & $45,13 \mathrm{ab}$ & 3,37 \\
\hline \multirow[t]{2}{*}{ Digest total } & 52,89 & 41,09 & 49,42 & 46,98 & 47,22 & 4,48 \\
\hline & \multicolumn{5}{|c|}{ Fibra em detergente ácido } & \\
\hline Digest ruminal & $45,69 \mathrm{a}$ & $36,15 \mathrm{ab}$ & $31,62 b$ & $36,05 \mathrm{ab}$ & $38,82 \mathrm{ab}$ & 3,82 \\
\hline \multirow[t]{2}{*}{ Digest total } & 49,71 & 42,41 & 38,29 & 36,31 & 40,53 & 5,31 \\
\hline & \multicolumn{6}{|c|}{ Energia Bruta } \\
\hline Digest ruminal & $39,86 b$ & $38,95 \mathrm{~b}$ & $50,74 \mathrm{ab}$ & $46,47 \mathrm{ab}$ & $56,66 \mathrm{a}$ & 4,1 \\
\hline Digest total & $68,28 b c$ & $67,26 \mathrm{c}$ & $71,74 \mathrm{abc}$ & $72,01 \mathrm{ab}$ & $76,08 \mathrm{a}$ & 1,5 \\
\hline
\end{tabular}

MGM: milho grosseiramente moído; MFM: milho finamente moído; MF310: milho floculado a 310g/1; M360: milho floculado a 360g/1; RM: raspa de mandioca; Digest: digestibilidade; EPM: erro padrão da média.

Médias seguidas de letras distintas na linha indicam diferença entre tratamentos $(P<0,05)$.

Aldrich et al. (1993), Oliveira et al. (1995) e Plascencia e Zinn (1996) demonstraram que o aumento da digestibilidade ruminal de amido eleva a digestibilidade no trato digestivo total. Estudos em que fontes de amido floculado foram comparadas com fontes de amido moído grosseiramente ou laminado a seco, a digestibilidade do amido no trato digestivo total foi maior nas fontes floculadas (Santos, 1996; Santos et al., 1999; Yu et al., 1998). Nocek e Tamminga (1991), em extensa revisão, mostraram que a quantidade de amido digerida no trato total é altamente associada à degradabilidade do amido no rúmen.

Houve efeito $(\mathrm{P}>0,05)$ da hora de amostragem nas variáveis de fermentação ruminal. Entretanto, não houve interação de hora e tratamento. As fontes de amido não influenciaram $(\mathrm{P}>0,05)$ a digestibilidade ruminal da FDN e da FDA (Tab. 3). As variáveis de fermentação ruminal indicaram que não houve efeito negativo do $\mathrm{pH}$ ruminal sobre a digestão de fibra. Os dados médios de $\mathrm{pH}$ ruminal se mantiveram acima de 6 , à exceção de 2 e 4 h após a alimentação no tratamento com raspa de mandioca, o que indica que não houve efeito na atividade das bactérias digestoras de fibra.

A concentração dos AGVs totais (Tab. 4) não diferiu $(\mathrm{P}>0,05)$ entre os tratamentos. Diversos autores (Aldrich et al., 1993; Joy et al., 1997; Lykos et al., 1997) também não observaram diferença na concentração de AGVs totais para dietas em que variava a proporção de amido degradável no rúmen. O milho floculado a $310 \mathrm{~g} / 1$ diminuiu $(\mathrm{P}<0,05)$ a proporção de ácido acético $\mathrm{e}$ butírico e aumentou $(\mathrm{P}<0,05)$ a de ácido propiônico. Estes efeitos estão refletidos na relação acetato:propionato, que é mais estreita neste tratamento. Plascencia e Zinn (1996) e Joy et al. (1997) verificaram diminuição no valor de ácido acético e aumento no de ácido propiônico com o aumento da degradabilidade ruminal do amido.

Os dados de degradabilidade in situ do amido (Tab. 5) são consistentes com os resultados obtidos na avaliação in vivo. A raspa de mandioca apresentou maior taxa de degradação do amido comparada ao milho moído. 
Tabela 4. Efeito das fontes e das formas de processamento do amido na fermentação ruminal

\begin{tabular}{lcccccc}
\hline \multirow{2}{*}{ Variáveis } & \multicolumn{5}{c}{ Tratamentos } & \multirow{2}{*}{ EPM } \\
\cline { 2 - 5 } & MMG & MMF & MF310 & MF360 & RM & \\
\hline pH ruminal & $6,36 \mathrm{abc}$ & $6,42 \mathrm{ab}$ & $6,31 \mathrm{bc}$ & $6,29 \mathrm{c}$ & $6,44 \mathrm{a}$ & 0,60 \\
AGVs & 131,9 & 126,5 & 133,3 & 134,5 & 128,1 & 19,7 \\
Totais, mM & $58,6 \mathrm{a}$ & $58,1 \mathrm{a}$ & $55,7 \mathrm{~b}$ & $57,8 \mathrm{a}$ & $55,8 \mathrm{~b}$ & 4,04 \\
Acético, \% & $24,2 \mathrm{~b}$ & $23,2 \mathrm{c}$ & $26,2 \mathrm{a}$ & $23,6 \mathrm{bc}$ & $23,4 \mathrm{bc}$ & 2,89 \\
Propiônico,\% & $12,7 \mathrm{c}$ & $13,5 \mathrm{~b}$ & $12,7 \mathrm{c}$ & $13,1 \mathrm{bc}$ & $14,7 \mathrm{a}$ & 2,42 \\
Butírico,\% & $2,42 \mathrm{~b}$ & $2,53 \mathrm{a}$ & $2,16 \mathrm{c}$ & $2,50 \mathrm{ab}$ & $2,45 \mathrm{ab}$ & 0,11 \\
Acético/propiônico & & & & & & \\
\hline
\end{tabular}

MGM: milho grosseiramente moído; MFM: milho finamente moído; MF310: milho floculado a 310g/l; M360: milho floculado a 360g/l; RM: raspa de mandioca; EPM: erro padrão da média; AGVs: ácidos graxos voláteis.

Médias seguidas de letras distintas na linha indicam diferença entre tratamentos $(P<0,05)$.

Tabela 5. Efeito das fontes e das formas de processamento na degradabilidade in situ do amido

\begin{tabular}{cccccc} 
Degradabilidade & \multicolumn{5}{c}{ Tratamentos } \\
\cline { 2 - 5 } & MM & MF310 & MF360 & RM & EPM $^{2}$ \\
\hline 0,02 & $87,5 \mathrm{~b}$ & $90,1 \mathrm{ab}$ & $92,5 \mathrm{ab}$ & $95,4 \mathrm{a}$ & 1,67 \\
0,05 & $73,7 \mathrm{~b}$ & $80,4 \mathrm{ab}$ & $84,24 \mathrm{a}$ & $89,7 \mathrm{a}$ & 2,6 \\
0,08 & $65,5 \mathrm{~b}$ & $73,8 \mathrm{ab}$ & $78,6 \mathrm{a}$ & $85,4 \mathrm{a}$ & 3,3 \\
$\mathrm{a}, \%$ & 29,3 & 38,6 & 47,4 & 52,0 & 7,6 \\
$\mathrm{~b}, \%$ & $73,4 \mathrm{~b}$ & $61,2 \mathrm{ab}$ & $53,1 \mathrm{ab}$ & $47,8 \mathrm{a}$ & 7,5 \\
$\mathrm{c}, \%$ & $0,07 \mathrm{c}$ & $0,10 \mathrm{~b}$ & $0,12 \mathrm{~b}$ & $0,22 \mathrm{a}$ & 0,01 \\
\hline
\end{tabular}

MM: milho moído; MF310: milho floculado a 310g/l; M360: milho floculado a 360g/l; RM: raspa de mandioca; EPM: erro padrão da média.

Médias seguidas de letras distintas nas linhas indicam diferença entre tratamentos $(\mathrm{P}<0,05)$.

\section{CONCLUSÕES}

As maiores digestibilidades do amido floculado e da raspa de mandioca aumentaram a digestibilidade da matéria seca e da matéria orgânica das dietas, sem influenciar na digestibilidade ruminal da fibra. O processo de floculação promove aumento da digestibilidade do amido do milho comparada à da moagem grossa. O amido presente na raspa de mandioca apresenta maior digestibilidade ruminal comparada à do amido do milho, independentemente da forma de processamento utilizada.

\section{REFERÊNCIAS BIBLIOGRÁFICAS}

ALDRICH, J.M.; MULLER, L.D.;VARGA, G.A. et al. Nonstructural carbohydrate and protein effects on rumen fermentation, nutrient flow, and performance of dairy cows. J. Dairy Sci., v.76, p.1091-1105, 1993.

GOERING, H.K.; VAN SOEST, P.J. (Eds). Forage fiber analysis (apparatus, reagents, procedures and some applications). Washington: USDA, 1970. 20p.
JOY, M.T.; DEPETERS, E.J.; FADEL, J.G. et al. Effects of corn processing on the site and extent of digestion in lactating cows. J. Dairy Sci., v.80, p.2087-2097, 1997.

LYKOS, T.; VARGAS, G.A.; CASPER, D. Varying degradation rates of total nonstrutural carbohydrates: Effects on ruminal fermentation, blood metabolites, and milk production and composition in high producing Holstein cows. $J$. Dairy Sci., v.80, p.3341-3355, 1997.

McALLISTER, T.A.; PHILLIPE, R.C.; RODE, L.M. et al. Effect of the protein matrix on the digestion of cereal grains by ruminal microorganisms. J. Anim. Sci., v.71, p.205-212, 1993.

NOCEK, J.E.; TAMMINGA, S. Site of digestion of starch in the gastrointestinal tract of dairy cows and its effect on milk and composition. $J$. Dairy Sci., v.74, p.3598-3629, 1991.

NUTRIENT requirements of dairy cattle. 7.ed. Washinton, DC: National Academic of Sciences, 2001.381p.

OFFICIAL methods of analysis. 15.ed. Washington, DC: AOAC, 1990. 
OLIVEIRA, J.S.; HUBER, J.T.; SIMAS, J.M. et al. Effect of sorghum grain processing on site and extent of digestation of starch in lactating dairy cows. J. Dairy Sci., v.78, p.1318-1327, 1995.

ORSKOV, E.R.; McDONALD, P. The estimation of protein degradability in the rumem from incubation measurements weighted according to rate of passage. J. Agric. Sci., v.92, p.499-503, 1979.

PLASCENCIA, A.; ZINN, R.A. Influence of flake density on the feeding value of steam processed corn in diets for lactating cows. $J$. Anim. Sci., v.74, p.310-316, 1996.

POORE, M.H.; MOORE, J.A.; SWINGLE, R.S. et al. Wheat straw or alfalfa hay in diets with $30 \%$ neutral detergent fiber for lactating Holstein cows. J. Dairy Sci., v.74, p.3152-3159, 1991.

SANTOS, F.A.P. Effect of sorghum grain processing and protein source on performance and nutrient utilization by lactating dairy cows. 1996. 89f. Thesis (PhD). University of Arizona, Tucson.

SANTOS, E.P.; HUBER, J.T.; THEURER, C.B. et al. Response of lactating dairy cows to steam flaked sorghum, steam flaked corn or steamrolled corn and protein sources of differing degradability. J. Dairy Sci., v.82, p.728-737, 1999.
SIMAS, J.M. Processamento de grãos para rações de vacas leiteiras. In: SIMPÓSIO SOBRE PRODUÇÃO ANIMAL: CONFINAMENTO DE BOVINOS, 9., 1997, Piracicaba. Anais... Piracicaba: FEALQ, 1997. p.7-32.

USER'S guide: statistics. Version 6. Cary, NC: SAS Institute, 1997. 846p.

VAN SOEST, P.J.; ROBERTSON, J.B.; LEWIS, B.A. Methods for dietary fiber, neutral detergent fiber and non-starch polysaccharides in relation to animal nutrition. J. Dairy Sci., v.74, p.35833597, 1991.

WILKERSON, V.A.; GLEIN, B.P.; McLEOD. K.R. Energy and nitrogen balance in lactating cows fed diets containing dry or high moisture corn in either rolled or ground form. J. Dairy Sci., v.80, p.2487-2496, 1997.

YU, P.; HUBER, J.T.; SANTOS, F.A.P. et al. Effects of ground, steam-flaked, and steam-rolled corn grains on performance of lactating cows. $J$. Dairy Sci., v.81, p.777-783, 1998.

ZEOULA, L.M.; CALDAS NETO, S.F. Recentes avanços em amido na nutrição de vacas leiteiras. In: SIMPÓSIO INTERNACIONAL EM BOVINOCULTURA DE LEITE: NOVOS CONCEITOS EM NUTRIÇÃO, 2., 2001. Lavras, Anais... Lavras: UFLA, 2001. p.199-228. 